\title{
Assessment of ovarian reserve using anti-Müllerian hormone levels in benign gynecologic conditions and surgical interventions: a systematic narrative review
}

\author{
Akira Iwase ${ }^{1,2^{*}}$, Tomoko Nakamura', Tatsuo Nakahara ${ }^{1}$, Maki Goto ${ }^{1}$ and Fumitaka Kikkawa ${ }^{1}$
}

\begin{abstract}
The usefulness of anti-Müllerian hormone (AMH) for the quantitative evaluation of ovarian reserve has been established. Therefore, serum AMH has been recently applied to the assessment of ovarian reserve outside infertility treatment. We conducted a computer-based search, using keywords, through the PubMed database from inception until May 2014 and summarized available studies evaluating ovarian damage caused by gynecologic diseases, such as endometriosis and ovarian tumor, as well as surgical interventions, such as cystectomy and uterine artery embolization (UAE), to discuss the usefulness of serum AMH. Most of the studies demonstrated a decline of serum AMH levels after cystectomy for endometriomas. It is not conclusive whether electrocoagulation or suturing is preferable. The effects of other gynecologic diseases and interventions, such as hysterectomy and UAE, on ovarian reserve are controversial. Serum AMH levels should be considered in determining the indication and selection of operative methods for benign gynecologic conditions.
\end{abstract}

Keywords: AMH, Cystectomy, Endometriosis, Ovarian reserve, UAE

\section{Background}

Benign gynecologic diseases are often implicated in fertility problems, and therefore, fertility-preserving interventions are required for such conditions. However, surgical interventions involving the uterus and ovaries have been demonstrated to possibly affect ovarian function, as these interventions might decrease ovarian tissue levels and blood supply to ovaries [1-3].

The potential ovarian function at a given point in time is now defined as the "ovarian reserve," which reflects the quality and quantity of follicles in the ovaries [4]. Therefore, interventions for gynecologic conditions aiming to preserve fertility as well as benign gynecologic diseases themselves must be assessed from the point of view of ovarian reserve.

\footnotetext{
* Correspondence: akiwase@med.nagoya-u.ac.jp

'Department of Obstetrics and Gynecology, Nagoya University Graduate School of Medicine, 65 Tsurumai-cho, Showa-ku, Nagoya 466-8550, Japan ${ }^{2}$ Department of Maternal and Perinatal Medicine, Nagoya University Hospital, 65 Tsurumai-cho, Showa-ku, Nagoya 466-8550, Japan
}

Follicle-stimulating hormone (FSH), a widely used marker, was found to be insufficient for predicting ovarian reserve after in vitro fertilization (IVF) [5]. Among newly developed ovarian reserve tests, the serum level of anti-Müllerian hormone (AMH) has been recognized as an improved and informative marker [6,7]. AMH is produced by granulosa cells from preantral and small antral follicles, and therefore, AMH levels indirectly represent the total number of follicles, as estimated by the number of early-growing-stage follicles [8,9]. AMH is reported to be a better marker than FSH and inhibin B, and it displays similar performance as the antral follicle count in predicting ovarian response [10]. One of the advantages of serum AMH is its lower inter-cycle variability, distinguishing this variable from other markers including FSH and inhibin B [11], although serum AMH levels are reported to vary slightly during the menstrual cycle [12]. Therefore, many researchers have begun using serum AMH levels to evaluate ovarian damage caused by surgical interventions, such as ovarian cystectomy and uterine artery embolization (UAE). Moreover, serum AMH levels 
from conception to menopause in healthy females were analyzed to assess the value of $\mathrm{AMH}$ in predicting reproductive lifespan [13].

In the current review, we mainly focused on the assessment of ovarian reserve after gynecologic interventions. We also included an assessment of the influence of gynecologic diseases, such as endometriosis and endometriomas, on ovarian reserve to discuss what mechanisms are associated with the disturbance of ovarian reserve. Other ovarian toxic interventions, such as chemotherapy and radiotherapy, were not included in the current review to maintain a focus on primary gynecologic conditions.

\section{Methods}

\section{Sources}

Articles were identified through a PubMed database search covering the period from database's inception through May 2014. We conducted a computer-based search of all articles published in English using the keywords "AMH/ anti-Müllerian hormone and ovarian reserve" and ["endometrioma," "endometriosis," "ovarian tumor," "ovarian cystectomy," "uterine artery embolization/UAE," "salpingectomy," or "hysterectomy"].

\section{Study selection}

We examined the 77 published studies identified using the aforementioned keywords. For inclusion, articles needed to describe the evaluation of ovarian reserve using serum AMH levels in relation to benign gynecologic conditions and/or interventions for such conditions. Abstracts and review articles were excluded. Articles evaluating ovarian reserve using other markers, such as inhibin B and the antral follicle count, were not included. Finally, 40 articles were chosen (22 for endometriomas/endometriosis, 6 for other ovarian tumors/ cysts, and 12 for other interventions). In the current review, we adopted the unit used in the original studies to display $\mathrm{AMH}$ levels. Values presented in $\mathrm{pmol} / \mathrm{L}$ can be converted to $\mathrm{ng} / \mathrm{mL}$ by dividing them by 7.14 .

\section{Results}

\section{Ovarian tumor, surgery, and intervention}

Surgical interventions involving the uterine adnexa can possibly cause damage to ovarian function because of the loss of the ovarian cortex and/or detrimental effects on blood supply to the ovaries [14]. Surgical procedures include cystectomy for endometriomas and other benign ovarian tumors, salpingectomy for hydrosalpinx, and UAE for uterine leiomyoma, all of which are often performed as part of infertility treatments. Therefore, declines of ovarian reserve after these interventions must be avoided as much as possible. Assessments of their influence on ovarian reserve using serum AMH levels may be helpful for improving these surgical interventions.
On the contrary, ovarian cysts/tumors themselves might affect ovarian reserve. Several published reports have investigated this point.

\section{Endometrioma, endometriosis and ovarian reserve}

The ovarian cortex surrounding endometriomas has been revealed to possibly cause a reduction in the volume of healthy tissue, a lower follicular density, and a loss of cortex-specific stroma [15-17]. These results suggest that endometriomas might result in diminished ovarian reserve. Lemos et al. first reported that infertile patients with minimal/mild endometriosis, categorized as revised American Society for Reproductive Medicine (rASRM) classification stage I/II [18], have decreased serum AMH levels compared to those in a control group who had tubal obstruction without endometriosis (1.26 \pm $0.7 \mathrm{ng} / \mathrm{mL}$ in the study group [median age, 29.5 years] vs. $2.02 \pm 0.72 \mathrm{ng} / \mathrm{mL}$ in the control group [median age, 30.5 years], mean $\pm \mathrm{SD} ; \mathrm{P}=0.004$ ) [19]. It is not likely that the patients recruited in this study had endometriomas because all patients had rASRM stage I/II endometriosis. Concerning endometriomas, Kim et al. demonstrated that patients with stage IV endometriosis with endometriomas displayed significantly lower $\mathrm{AMH}$ levels than age- and BMI-matched controls $(2.1 \pm 0.3 \mathrm{ng} / \mathrm{mL}$ vs. $3.1 \pm 0.4 \mathrm{ng} / \mathrm{mL}$, mean \pm SEM; $P=0.02$ ) [20]. Similarly, it has been reported that $\mathrm{AMH}$ levels are lower in patients with stage III/IV endometriosis without prior ovarian surgery than in controls $(0.97 \pm 0.59 \mathrm{ng} / \mathrm{mL}$ in the study group [mean age, $33.6 \pm 1.9$ years] vs. $1.72 \pm 0.63 \mathrm{ng} / \mathrm{mL}$ in the control group [mean age, $32.6 \pm 2.0$ years], mean $\pm \mathrm{SD} ; \mathrm{P}=0.001$ ) [21]. Uncu et al. also reported lower AMH levels in patients with endometrioma than in age-matched controls (endometrioma vs. controls: $2.81 \pm 2.15 \mathrm{ng} / \mathrm{mL}$ vs. $4.20 \pm$ $2.26 \mathrm{ng} / \mathrm{mL}$, mean $\pm \mathrm{SD} ; \mathrm{P}=0.002$ ) [22]. In this study, the unilateral endometrioma group exhibited lower $\mathrm{AMH}$ levels than the bilateral endometrioma group. However, a cross-sectional study including 313 women with a diagnosis of endometriosis and 413 women without endometriosis (control) identified no difference in serum AMH levels related to the type of endometriosis excluding women who had a past history of surgery for endometriomas $(4.1 \pm 3.4 \mathrm{ng} / \mathrm{mL}$ for the control group, $4.5 \pm 3.6 \mathrm{ng} /$ $\mathrm{mL}$ for the superficial peritoneal lesion group, $3.8 \pm$ $2.9 \mathrm{ng} / \mathrm{mL}$ for the endometrioma group, $3.4 \pm 3.0 \mathrm{ng} / \mathrm{mL}$ for the deep infiltrating endometriosis group, mean $\pm \mathrm{SD}$; $\mathrm{P}=0.06$ ) [23].

\section{Surgery for endometrioma}

Unlike the controversy regarding the influence of an endometrioma itself on ovarian reserve, it appears conclusive that cystectomy for endometriomas diminishes ovarian reserve. Chang et al. and Iwase et al. first reported that cystectomy for endometriomas leads to a greater 
decrease of serum AMH levels than cystectomy for other benign ovarian tumors $[24,25]$. Subsequently, several similar studies have been published. Among these, only 1 study, in which preoperative serum AMH levels were lower for patients' ages than those in the other studies, demonstrated that cystectomy for endometriomas did not cause significant changes in serum AMH levels [26,27]. These studies have already been reviewed and metaanalyzed, which led to the conclusion that cystectomy for endometriomas may cause a decline of ovarian reserve $[28,29]$. In addition to the studies comparing preoperative and postoperative AMH levels, a cross-sectional study also demonstrated that AMH levels were significantly lower in women who previously underwent endometrioma surgery, irrespective of whether endometriomas were present at the time of the study $(\mathrm{P}<0.05)$ [23].

Measurements of serum AMH levels make the quantitative evaluation of the effects of surgery on ovarian reserve possible. Consequently, several issues have emerged regarding surgery for endometrioma and ovarian reserve. The first issue is the incidence of post-surgical decreases in ovarian reserve. Laparoscopic cystectomy for bilateral endometriomas has been reported to possibly cause a greater decline of serum AMH levels than unilateral cystectomy $[24,25]$. Hirokawa et al. reported that the serum AMH levels 1 month after surgery compared with the preoperative levels were $24.7 \pm 32.5$ and $62.8 \pm 29.6 \%$ lower for patients with unilateral and bilateral tumors, respectively $(\mathrm{P}<0.001)[30]$. They also found that severe endometriosis with higher rASRM scores tends to cause greater declines of serum AMH levels after surgery. Kitajima et al. reported that the decline of serum AMH levels within 3 months after surgery was significantly greater in women with an excised cyst wall that contained normal ovarian tissue than in women without healthy ovarian tissue in the excised cyst wall $(42.0 \pm$ $32.9 \%$ vs. $8.9 \pm 13.4 \%$; $P=0.01$ ) [31]. In a 1-year follow up study, the immediate postsurgical decline of serum AMH levels was revealed to be possibly related to the reduction of cortex volume from the excision, and the medium/long-term decrease was believed to be caused by other factors, including reduced blood supply to the ovaries. [32]. Recently, a study of 193 patients who underwent laparoscopic cystectomy for endometrioma demonstrated that postoperative AMH levels significantly decreased after surgery irrespective of age $(\leq 38$ years, $\mathrm{P}<0.001$; $>38$ years, $\mathrm{P}<0.001)$, cyst size $(>3 \mathrm{~cm}, \mathrm{P}=$ 0.018 ; $\leq 3 \mathrm{~cm}, \mathrm{P}=0.022$ ), and laterality (unilateral, $\mathrm{P}<0.001$; bilateral, $\mathrm{P}<0.001$ ) [33].

Another interesting issue is how various surgical methods affect postoperative AMH levels. Cauterization and vaporization of the cyst wall might have an advantage in sparing ovarian reserve. The 3-step technique, consisting of irrigation in the first laparoscopy, followed by gonadotropin-releasing hormone agonists and vaporization in the second laparoscopy, resulted in a lower postsurgical decline of $\mathrm{AMH}$ levels than endometrioma stripping $(3.9 \pm 0.4$ and $2.9 \pm 0.2 \mathrm{ng} / \mathrm{mL}$ with stripping vs. $4.5 \pm 0.4$ and $3.99 \pm 0.6 \mathrm{ng} / \mathrm{mL}$ with the 3-step technique, mean \pm SEM at baseline and 6 months after surgery; $\mathrm{P}=0.026$ in the stripping group) [34]. Bipolar electrocoagulation might damage the cortex of ovaries. Ferrero et al. performed a randomized controlled trial (RCT) to compare serum AMH levels following hemostasis by bipolar coagulation versus suturing after laparoscopic cystectomy for bilateral endometriomas [35]. They found no significant difference in the mean percentage decrease of AMH levels in the 2 groups after 3, 6, and 12 months of follow-up. Another RCT was performed to compare hemostatic matrix with bipolar electrocoagulation after laparoscopic cystectomy for unilateral endometrioma [36]. Serum AMH levels in the bipolar coagulation group were significantly lower at 1 month after surgery and similar at 3 months after surgery compared to those in the hemostatic matrix group (hemostatic matrix vs. bipolar coagulation: $3.73 \pm 1.50 \mathrm{ng} / \mathrm{mL}$ vs. $3.66 \pm 1.20 \mathrm{ng} / \mathrm{mL}$ preoperative, $2.72 \pm 1.49 \mathrm{ng} / \mathrm{mL}$ vs. $1.64 \pm 0.93 \mathrm{ng} / \mathrm{mL}$ in the 1 st month, and $3.07 \pm 1.43 \mathrm{ng} / \mathrm{mL}$ vs. $2.84 \pm 1.12 \mathrm{ng} / \mathrm{mL}$ in the $3 \mathrm{rd}$ month, mean \pm SD; $\mathrm{P}=0.001$ and $\mathrm{P}=0.467$ in the 1 st and 3 rd months, respectively). Zaitoun et al. prospectively compared laparoscopic cystectomy with bipolar coagulation and laparotomic cystectomy with sutures. Only the laparoscopic cystectomy group displayed a significant decrease of AMH levels $(4.5 \pm 0.8,2.4 \pm 0.5,2.7 \pm 0.5$, and $2.5 \pm$ $0.4 \mathrm{ng} / \mathrm{mL}$ in the laparoscopic group vs. $4.6 \pm 0.9,4.5 \pm 0.9$, $4.4 \pm 0.9$, and $4.5 \pm 0.9 \mathrm{ng} / \mathrm{mL}$ in the laparotomy group preoperatively and 6,12 , and 18 months after surgery, respectively; mean $\pm \mathrm{SD}, \mathrm{P}=0.8, \mathrm{P}<0.005, \mathrm{P}<0.005$, and $\mathrm{P}<0.005$ preoperatively and 6,12 , and 18 months after surgery, respectively) [37].

Another issue is the recovery of serum AMH levels after surgery for endometriomas. AMH is produced by primary, preantral, and small antral follicles but not primordial follicles [9]. If rearrangements of follicle cohorts from a healthy primordial follicle pool occur, then serum AMH levels that decreased as a result of surgery could recover. Two early studies indicated that serum AMH levels might be restored to some extent by 1 week, 1 month, and 3 months after cystectomy for endometriomas $[24,38]$. In the aforementioned RCT, AMH levels, especially in the bipolar coagulation group, tended to recover at 3 months after surgery compared with 1 month after surgery [36]. On the contrary, several studies demonstrated that serum AMH levels gradually decreased or remained depressed $[22,35,39,40]$. Celik et al. assessed serum AMH levels preoperatively and at 6 weeks and 6 months after surgery and reported that AMH levels gradually decreased patients with bilateral tumors or those 
with cyst diameters $\geq 5 \mathrm{~cm}$ [39]. Sugita et al. reported that serum AMH levels could be higher or lower 12 months after surgery compared to those 1 month after surgery [32].

\section{Other benign ovarian cysts}

The effects of cystectomy for benign ovarian tumors on AMH levels have been assessed in a few studies. Iwase et al. reported that laparoscopic cystectomy for nonendometriomas (15 cases of unilateral tumors and 5 cases of bilateral tumors) caused a lesser, but significant, decline of AMH levels (3.92 and $3.29 \mathrm{ng} / \mathrm{mL}$ before and after cystectomy, respectively, median; $\mathrm{P}=0.044$ ) [25]. Similarly, another study reported that serum AMH levels were lower 1 week after laparoscopic cystectomy for nonendometriotic cysts $(69.2 \%$ of the preoperative AMH levels; $\mathrm{P}<0.05$ ) [24]. Jang et al. recently reconfirmed the results from Iwase and Chang [41]. Thus far, only 1 prospective randomized study has compared serum AMH levels after cystectomy for unilateral non-endometriotic cysts using laparoscopy and laparotomy [42]. Significant differences were found in AMH levels between the laparoscopy and laparotomy groups at 1, 3, and 6 cycles after cystectomy (4.2, 3.2, 2.6 , and $2.4 \mathrm{ng} / \mathrm{mL}$ in the laparoscopy group vs. 4.6, $3.7,3.5$, and $3.6 \mathrm{ng} / \mathrm{mL}$ in the laparotomy group before and 1, 3, and 6 cycles after cystectomy, respectively, mean; $\mathrm{P}=0.180, \mathrm{P}=0.004, \mathrm{P}<0.001$, and $\mathrm{P}<0.001$, respectively). No significant difference was observed in preoperative serum AMH levels between the mature cystic teratoma group and age- and BMImatched controls $(4.0 \pm 0.5 \mathrm{ng} / \mathrm{mL}$ vs. $4.0 \pm 0.5 \mathrm{ng} / \mathrm{mL}$, mean \pm SEM; not significant) [20]. The decline rates of serum AMH levels after cystectomy for benign ovarian tumors have been reported to be lower than those observed after cystectomy for endometriomas. Chang et al. reported that the decline in serum AMH levels at 1 week after laparoscopic cystectomy was smaller for non-endometriotic cysts than for endometrioma (69.2\% vs. $33.9 \%$ of preoperative AMH levels; $\mathrm{P}=0.028$ ) [24]. A similar tendency was reported by Iwase et al. (the extent of decline compared to preoperative levels: $16.1 \%$ in the benign ovarian tumor group vs. $24.9 \%$ in the endometrioma group) [25]. On the contrary, it was recently reported that the rate of AMH decline at 3 months after laparoscopic cystectomy did not differ between the endometrioma group and the other benign ovarian cyst group $(36.64 \pm 29.20 \%$ vs. $30.58 \pm 29.66 \%$ of the preoperative level; $\mathrm{P}=0.36$ ) [43].

\section{Other interventions that affect ovarian reserve}

Hydrosalpinx can reduce the likelihood of pregnancy after IVF. Therefore, salpingectomy of diseased fallopian tubes before IVF should be considered [44]. Salpingectomy might result in decreased blood supply to the ovaries. However, the ovarian response after salpingectomy has been inconsistent $[45,46]$. In a cross-sectional study, no significant differences were found in serum AMH levels among patients with varying tubal status, including 26, 34, 23, and 51 patients who underwent bilateral salpingectomy, unilateral salpingectomy, bilateral interruption in the proximal oviducts, and bilateral oviduct obstruction, respectively [47]. On the contrary, Grynnerup et al. reported that AMH levels were significantly lower in the salpingectomy group than in the nonsalpingectomy group (16.1 pmol/L [median age, 34 years] vs. $23.4 \mathrm{pmol} / \mathrm{L}$ [median age, 33 years], median; $\mathrm{P}=0.04$ ) [48]. Sequential assessments of serum AMH levels did not reveal statistically significant differences before and after laparoscopic coagulation and dissection of the proximal tubes $(1.548 \mathrm{ng} / \mathrm{mL}$ preoperatively vs. $1.481 \mathrm{ng} / \mathrm{mL}$ 3 months after surgery, median; $\mathrm{P}=0.079$ ) [49]. Similarly, research illustrated that serum $\mathrm{AMH}$ levels were not affected by tubal ligation $(1.43 \mathrm{ng} / \mathrm{mL}$ preoperatively vs. $1.30 \mathrm{ng} / \mathrm{mL} 12$ months after surgery, median; $\mathrm{P}=0.23)[50]$.

Hysterectomy, even if the ovaries are preserved, has been reported to possibly cause adverse effects on ovarian function, which might shorten the time to menopause $[51,52]$. Atabekoglu et al. reported that serum AMH levels tended to decline more at 4 months after hysterectomy compared to those in controls who did not undergo hysterectomy $(1.46 \pm 2.02$ to $0.62 \pm 0.9 \mathrm{ng} / \mathrm{mL}$ in the hysterectomy group vs. $1.53 \pm 1.82$ to $1.26 \pm 1.78 \mathrm{ng} / \mathrm{mL}$ in the controls, mean $\pm \mathrm{SD}, \mathrm{P}=0.73$ and $\mathrm{P}=0.262$ before and after surgery, respectively) [53]. The authors concluded that the decrease in ovarian reserve after hysterectomy is possibly caused by hypoxia as a result of the interruption of the uterine arteries. However, Lee at al. revealed that hysterectomy did not affect ovarian artery blood flow or serum AMH levels $(1.80 \pm 1.81 \mathrm{ng} / \mathrm{mL}$ preoperatively in women aged $44.2 \pm 3.5$ years vs. $1.52 \pm 1.72 \mathrm{ng} / \mathrm{ml}$ at 3 months after hysterectomy, mean $\pm \mathrm{SD} ; \mathrm{P}=0.805$ ) [54]. Wang et al. demonstrated that serum AMH levels significantly declined 3 months following hysterectomy, whereas those 3 months after myomectomy were similar to the preoperative levels $(1.08 \pm 0.77 \mathrm{ng} / \mathrm{mL}$ vs. $0.81 \pm$ $0.55 \mathrm{ng} / \mathrm{mL}$ in the hysterectomy group; $\mathrm{P}<0.01 ; 1.54 \pm$ $0.95 \mathrm{ng} / \mathrm{mL}$ vs. $1.50 \pm 0.58 \mathrm{ng} / \mathrm{mL}$ in the myomectomy group; $\mathrm{P}=0.07$; mean $\pm \mathrm{SD}$ preoperatively and 3 months after surgery) [55]. In another point of view, prophylactic salpingectomy with total laparoscopic hysterectomy (TLH) did not cause a significant decrease of AMH levels compared to those observed after standard TLH with adnexal observation $(-0.06 \pm 0.1 \mathrm{ng} / \mathrm{mL}$ vs. $-0.08 \pm$ $0.1 \mathrm{ng} / \mathrm{mL} \triangle \mathrm{AMH}$ for TLH with vs. without salpingectomy, mean $\pm \mathrm{SD} ; \mathrm{P}=0.35$ ) [56]. This result was reconfirmed in an RCT $(2.26 \pm 2.72 \mathrm{ng} / \mathrm{mL}$ and $1.86 \pm 1.99 \mathrm{ng} /$ $\mathrm{mL}$ in the bilateral salpingectomy with hysterectomy group 
vs. $2.25 \pm 2.57$ and $1.82 \pm 3.12 \mathrm{ng} / \mathrm{mL}$ in the no salpingectomy group, mean \pm SD at baseline and 3 months after surgery; $\mathrm{P}=0.99$ and $\mathrm{P}=0.97$, respectively) [57].

UAE has been introduced as an effective treatment for severe hemorrhage related to pregnancy and has been proposed as a replacement for hysterectomy for some patients with uterine leiomyoma [58,59]. However, the possible decline of ovarian reserve after UAE remains controversial. Hehenkamp et al. measured serum AMH levels at baseline and at several time points during follow-up after UAE and hysterectomy and found that $\mathrm{AMH}$ levels remained significantly lower during the follow-up period in the UAE group but not in the hysterectomy group [60]. Similar results were reported by Arthur et al., who compared UAE and laparoscopic myomectomy $(2.17 \mathrm{ng} / \mathrm{mL}$ after laparoscopic myomectomy vs. $0.78 \mathrm{ng} / \mathrm{mL}$ after UAE, median; $\mathrm{P}=0.01$ ) [61]. On the contrary, the combination of UAE and local methotrexate for interstitial pregnancies did not appear to reduce ovarian reserve based on AMH levels, although only 3 cases were analyzed [62]. Figure 1 presents the gynecologic diseases and interventions in which assessments of ovarian reserve using AMH have been reported.

\section{Discussion}

\section{Main findings and limitations}

As we reviewed manuscripts for this article, the following results were demonstrated: 1) the influence of endometriosis/endometrioma itself on ovarian reserve remains controversial, 2) cystectomy for endometriomas tends to reduce $\mathrm{AMH}$ levels more severely than that for other types of benign ovarian tumors, especially for bilateral or severe disease, 3) cystectomy and bipolar coagulation in endometrioma surgery could be the factors that decrease ovarian reserve. However, it is not conclusive which surgical method is preferable from the point of view of ovarian reserve, 4) although hysterectomy, salpingectomy, and UAE might affect ovarian reserve, there is insufficient evidence to draw a conclusion.

One of the limitations of our study is the high heterogeneity of the included articles. Serum AMH levels were primarily affected by the recruited patients' ages, which differed among the studies. Another limitation is that the significance of the decrease in serum AMH levels after the interventions is not conclusive, as the changes were possibly encompassed by the wide normal range for serum AMH [13]. However, this review involved the systematic collection of articles to assess ovarian reserve in relation to gynecologic diseases and interventions and the narrative evaluation of the articles.

\section{Interpretation and future perspective}

The clinical potential of measuring serum AMH levels has been evaluated in a wide range of healthcare issues outside assisted reproductive technology, including assessments for ovarian damage caused by chemotherapy, radiation, surgery, and possible predictors for menopause $[63,64]$.

In the current review, we focused on the usefulness of $\mathrm{AMH}$ for evaluating ovarian damage caused by gynecologic interventions, such as surgery and embolization. Regarding endometriomas, 2 randomized studies illustrated that stripping was superior to vaporization or coagulation of the cyst wall in terms of the rates of spontaneous pregnancy and disease recurrence [65-67]. However, vaporization or coagulation has been demonstrated to be more favorable in terms of ovarian reserve [14]. Therefore, the increasingly widespread use of AMH measurements has

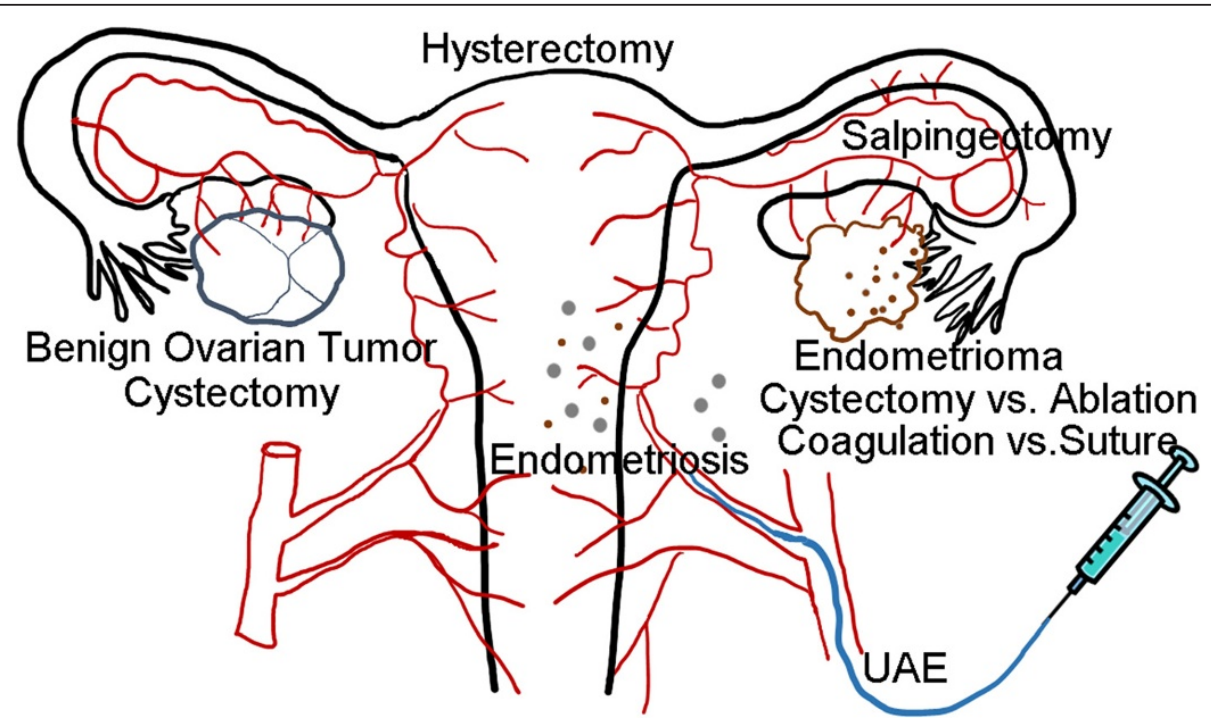

Figure 1 Possible factors that affect ovarian reserve in patients with benign gynecologic conditions. UAE, uterine artery embolization. 
stimulated research to identify the most appropriate surgical methods for treating endometriomas. As we previously mentioned, several studies revealed that cystectomy for endometriomas causes a decrease of ovarian reserve, especially in cases of bilateral disease. Disturbance of the blood supply has been considered one of the reasons to affect ovarian reserve in endometrioma cystectomy. A small number of studies revealed that suturing or using hemostatic materials without bipolar electrocoagulation might be preferable in the preserving ovarian reserve. Further studies, including those of the rates of pregnancy and recurrence after surgery, are needed to evaluate the true usability of serum AMH levels after endometrioma surgery.

In addition to endometrioma surgery, surgical interventions that might cause ovarian damage should be evaluated in terms of ovarian reserve. It is controversial whether cystectomy for benign ovarian tumors excluding endometriomas negatively affects ovarian reserve. However, the influence should be less than that of cystectomy for endometriomas. UAE is performed for leiomyoma and postpartum hemorrhage. Possible damage to the ovaries is a problem if these patients desire pregnancy in the future. Declines of ovarian reserve possibly caused by salpingectomy, which is occasionally performed for ectopic pregnancy and hydrosalpinx, could also be an issue. Ovarian function is important from the point of view of women's healthcare. Therefore, considering ovarian function after hysterectomy, the assessment for ovarian reserve using $\mathrm{AMH}$ has a role. The studies thus far have not demonstrated a huge influence, although the impact of such interventions on ovarian reserve by is not conclusive.

\section{Conclusions}

In conclusion, serum AMH is helpful for counseling patients who desire future fertility but have benign gynecologic conditions that may require surgical interventions. Serum AMH levels may be preferred in determining the indication and selection of operative methods for benign gynecologic conditions, especially endometriomas. However, there is little available information regarding the correlation between the possibility of live birth and serum AMH levels before and after interventions. Further studies are required to investigate whether and how serum $\mathrm{AMH}$ levels in patients with benign gynecologic conditions are relevant to prospective live birth.

\footnotetext{
Abbreviations

AMH: Anti-Müllerian hormone; FSH: Follicle-stimulating hormone; IVF: In vitro fertilization; rASRM: Revised american society for reproductive medicine; RCT: Randomized controlled trial; TLH: Total laparoscopic hysterectomy; UAE: Uterine artery embolization.
}

\section{Competing interests}

The authors declare that they have no competing interests.

\section{Authors' contributions}

Al contributed to data acquisition, analysis, and interpretation and participated in drafting the manuscript. TN, TN, and MG contributed to data acquisition, analysis, and interpretation. FK participated in the design of the review and provided final approval of the version to be published. All authors read and approved the final manuscript.

Received: 24 September 2014 Accepted: 14 December 2014 Published: 15 December 2014

\section{References}

1. La Torre R, Montanino-Oliva M, Marchiani E, Boninfante M, Montanino G, Cosmi EV: Ovarian blood flow before and after conservative laparoscopic treatment for endometrioma. Clin Exp Obstet Gynecol 1998, 25:12-14

2. Marconi G, Vilela M, Quintana R, Sueldo C: Laparoscopic ovarian cystectomy of endometriomas does not affect the ovarian response to gonadotropin stimulation. Fertil Steril 2002, 78:876-878.

3. Muzii L, Bianchi A, Croce C, Manci N, Panici PB: Laparoscopic excision of ovarian cysts: is the stripping technique a tissue-sparing procedure? Fertil Steril 2002, 77:609-614.

4. Broekmans FJ, Kwee J, Hendriks DJ, Mol BW, Lambalk CB: A systematic review of tests predicting ovarian reserve and IVF outcome. Hum Reprod Update 2006, 12:685-718.

5. Bancsi LF, Broekmans FJ, Mol BW, Habbema JD, te Velde ER: Performance of basal follicle-stimulating hormone in the prediction of poor ovarian response and failure to become pregnant after in vitro fertilization: a meta-analysis. Fertil Steril 2003, 79:1091-1100.

6. Loh JS, Maheshwari A: Anti-Mullerian hormone-is it a crystal ball for predicting ovarian ageing? Hum Reprod 2011, 26:2925-2932.

7. Nelson SM: Biomarkers of ovarian response: current and future applications. Fertil Steril 2013, 99:963-969.

8. Durlinger AL, Gruijters MJ, Kramer P, Karels B, Ingraham HA, Nachtigal MW, Uilenbroek JT, Grootegoed JA, Themmen AP: Anti-Mullerian hormone inhibits initiation of primordial follicle growth in the mouse ovary. Endocrinology 2002, 143:1076-1084.

9. Weenen C, Laven JS, Von Bergh AR, Cranfield M, Groome NP, Visser JA Kramer P, Fauser BC, Themmen AP: Anti-Mullerian hormone expression pattern in the human ovary: potential implications for initial and cyclic follicle recruitment. Mol Hum Reprod 2004, 10:77-83.

10. La Marca A, Sighinolfi G, Radi D, Argento C, Baraldi E, Artenisio AC, Stabile G, Volpe A: Anti-Mullerian hormone (AMH) as a predictive marker in assisted reproductive technology (ART). Hum Reprod Update 2010, 16:113-130.

11. van Disseldorp J, Lambalk CB, Kwee J, Looman CW, Eijkemans MJ, Fauser BC, Broekmans FJ: Comparison of inter- and intra-cycle variability of anti-Mullerian hormone and antral follicle counts. Hum Reprod 2010, 25:221-227.

12. Hadlow N, Longhurst K, McClements A, Natalwala J, Brown SJ, Matson PL: Variation in antimullerian hormone concentration during the menstrual cycle may change the clinical classification of the ovarian response. Fertil Steril 2013, 99:1791-1797.

13. Kelsey TW, Wright P, Nelson SM, Anderson RA, Wallace WH: A validated model of serum anti-mullerian hormone from conception to menopause. PLoS One 2011, 6:e22024

14. Somigliana E, Vercellini P, Vigano P, Ragni G, Crosignani PG: Should endometriomas be treated before IVF-ICSI cycles? Hum Reprod Update 2006, 12:57-64.

15. Kitajima M, Defrere S, Dolmans MM, Colette S, Squifflet J, Van Langendonckt A, Donnez J: Endometriomas as a possible cause of reduced ovarian reserve in women with endometriosis. Fertil Steril 2011, 96:685-691.

16. Maneschi F, Marasa L, Incandela S, Mazzarese M, Zupi E: Ovarian cortex surrounding benign neoplasms: a histologic study. Am J Obstet Gynecol 1993, 169:388-393.

17. Schubert B, Canis M, Darcha C, Artonne C, Pouly JL, Dechelotte P, Boucher $D$, Grizard G: Human ovarian tissue from cortex surrounding benign cysts: a model to study ovarian tissue cryopreservation. Hum Reprod 2005, 20:1786-1792

18. Revised American Fertility Society classification of endometriosis. Fertil Steril 1985, 43:351-352. 
19. Lemos NA, Arbo E, Scalco R, Weiler E, Rosa V, Cunha-Filho JS: Decreased anti-Mullerian hormone and altered ovarian follicular cohort in infertile patients with mild/minimal endometriosis. Fertil Steril 2008, 89:1064-1068.

20. Kim JY, Jee BC, Suh CS, Kim SH: Preoperative serum anti-mullerian hormone level in women with ovarian endometrioma and mature cystic teratoma. Yonsei Med J 2013, 54:921-926.

21. Pacchiarotti A, Frati P, Milazzo GN, Catalano A, Gentile V, Moscarini M: Evaluation of serum anti-Mullerian hormone levels to assess the ovarian reserve in women with severe endometriosis. Eur J Obstet Gynecol Reprod Biol 2014, 172:62-64

22. Uncu G, Kasapoglu I, Ozerkan K, Seyhan A, Oral Yilmaztepe A, Ata B: Prospective assessment of the impact of endometriomas and their removal on ovarian reserve and determinants of the rate of decline in ovarian reserve. Hum Reprod 2013, 28:2140-2145.

23. Streuli I, de Ziegler D, Gayet V, Santulli P, Bijaoui G, de Mouzon J, Chapron $\mathrm{C}$ : In women with endometriosis anti-Mullerian hormone levels are decreased only in those with previous endometrioma surgery. Hum Reprod 2012, 27:3294-3303.

24. Chang HJ, Han SH, Lee JR, Jee BC, Lee BI, Suh CS, Kim SH: Impact of laparoscopic cystectomy on ovarian reserve: serial changes of serum anti-Mullerian hormone levels. Fertil Steril 2010, 94:343-349.

25. Iwase A, Hirokawa W, Goto M, Takikawa S, Nagatomo Y, Nakahara T, Manabe S, Kikkawa F: Serum anti-Mullerian hormone level is a useful marker for evaluating the impact of laparoscopic cystectomy on ovarian reserve. Fertil Steril 2010, 94:2846-2849.

26. Ercan CM, Duru NK, Karasahin KE, Coksuer H, Dede M, Baser I: Ultrasonographic evaluation and anti-mullerian hormone levels after laparoscopic stripping of unilateral endometriomas. Eur J Obstet Gynecol Reprod Biol 2011, 158:280-284.

27. Ercan CM, Sakinci M, Duru NK, Alanbay I, Karasahin KE, Baser I: Antimullerian hormone levels after laparoscopic endometrioma stripping surgery. Gynecol Endocrinol 2010, 26:468-472.

28. Raffi F, Metwally M, Amer S: The impact of excision of ovarian endometrioma on ovarian reserve: a systematic review and meta-analysis. J Clin Endocrinol Metab 2012, 97:3146-3154.

29. Somigliana E, Berlanda N, Benaglia L, Vigano P, Vercellini P, Fedele L: Surgical excision of endometriomas and ovarian reserve: a systematic review on serum antimullerian hormone level modifications. Fertil Steril 2012, 98:1531-1538.

30. Hirokawa W, Iwase A, Goto M, Takikawa S, Nagatomo Y, Nakahara T, Bayasula B, Nakamura T, Manabe S, Kikkawa F: The post-operative decline in serum anti-Mullerian hormone correlates with the bilaterality and severity of endometriosis. Hum Reprod 2011, 26:904-910

31. Kitajima M, Khan KN, Hiraki K, Inoue T, Fujishita A, Masuzaki H: Fertil Steril 2011, 95:2589 e2581-2591 e2581

32. Sugita A, Iwase A, Goto M, Nakahara T, Nakamura T, Kondo M, Osuka S, Mori M, Saito A, Kikkawa F: One-year follow-up of serum antimullerian hormone levels in patients with cystectomy: are different sequential changes due to different mechanisms causing damage to the ovarian reserve? Fertil Steril 2013, 100:516 e513-522 e513.

33. Alborzi S, Keramati P, Younesi M, Samsami A, Dadras N: The impact of laparoscopic cystectomy on ovarian reserve in patients with unilateral and bilateral endometriomas. Fertil Steril 2014, 101:427-434.

34. Tsolakidis D, Pados G, Vavilis D, Athanatos D, Tsalikis T, Giannakou A Tarlatzis BC: The impact on ovarian reserve after laparoscopic ovarian cystectomy versus three-stage management in patients with endometriomas: a prospective randomized study. Fertil Steril 2010, 94:71-77.

35. Ferrero S, Venturini PL, Gillott DJ, Remorgida V, Maggiore ULR: Hemostasis by bipolar coagulation versus suture after surgical stripping of bilatera ovarian endometriomas: a randomized controlled trial. J Minim Invasive Gynecol 2012, 19:722-730.

36. Sonmezer M, Taskin S, Gemici A, Kahraman K, Ozmen B, Berker B, Atabekoglu C: Can ovarian damage be reduced using hemostatic matrix during laparoscopic endometrioma surgery? A prospective, randomized study. Arch Gynecol Obstet 2013, 287:1251-1257.

37. Zaitoun MM, El Behery MM: Comparing long term impact on ovarian reserve between laparoscopic ovarian cystectomy and open laprotomy for ovarian endometrioma. J Ovarian Res 2013, 6:76.
38. Lee DY, Young Kim N, Jae Kim M, Yoon BK, Choi D: Effects of laparoscopic surgery on serum anti-Mullerian hormone levels in reproductive-aged women with endometrioma. Gynecol Endocrinol 2011, 27:733-736.

39. Celik HG, Dogan E, Okyay E, Ulukus C, Saatli B, Uysal S, Koyuncuoglu M: Effect of laparoscopic excision of endometriomas on ovarian reserve: serial changes in the serum antimullerian hormone levels. Fertil Steril 2012, 97:1472-1478.

40. Urman B, Alper E, Yakin K, Oktem O, Aksoy S, Alatas C, Mercan R, Ata B: Removal of unilateral endometriomas is associated with immediate and sustained reduction in ovarian reserve. Reprod Biomed Online 2013, 27:212-216.

41. Jang WK, Lim SY, Park JC, Lee KR, Lee A, Rhee JH: Surgical impact on serum anti-Mullerian hormone in women with benign ovarian cyst: A prospective study. Obstet Gynecol Sci 2014, 57:121-127.

42. Mohamed ML, Nouh AA, El-Behery MM, Mansour SA: Effect on ovarian reserve of laparoscopic bipolar electrocoagulation versus laparotomic hemostatic sutures during unilateral ovarian cystectomy. Int J Gynaecol Obstet 2011, 114:69-72

43. Kwon SK, Kim SH, Yun SC, Kim DY, Chae HD, Kim CH, Kang BM: Decline of serum antimullerian hormone levels after laparoscopic ovarian cystectomy in endometrioma and other benign cysts: a prospective cohort study. Fertil Steril 2014, 101:435-441.

44. Johnson N, van Voorst S, Sowter MC, Strandell A, Mol BW: Surgical treatment for tubal disease in women due to undergo in vitro fertilisation. Cochrane Database Syst Rev 2010, (1):CD002125. doi: 10.1002/14651858.CD002125.pub3.

45. Orvieto R, Saar-Ryss B, Morgante G, Gemer O, Anteby EY, Meltcer S: Does salpingectomy affect the ipsilateral ovarian response to gonadotropin during in vitro fertilization-embryo transfer cycles? Fertil Steril 2011, 95:1842-1844.

46. Strandell A, Lindhard A, Waldenstrom U, Thorburn J: Prophylactic salpingectomy does not impair the ovarian response in IVF treatment. Hum Reprod 2001, 16:1135-1139.

47. Ni L, Sadiq S, Mao Y, Cui Y, Wang W, Liu J: Influence of various tubal surgeries to serum antimullerian hormone level and outcome of the subsequent IVF-ET treatment. Gynecol Endocrinol 2013, 29:345-349.

48. Grynnerup AG, Lindhard A, Sorensen S: Anti-Mullerian hormone levels in salpingectomized compared with nonsalpingectomized women with tubal factor infertility and women with unexplained infertility. Acta Obstet Gynecol Scand 2013, 92:1297-1303.

49. Ercan CM, Sakinci M, Coksuer H, Keskin U, Tapan S, Ergun A: Ovarian reserve testing before and after laparoscopic tubal bipolar electrodesiccation and transection. Eur J Obstet Gynecol Reprod Biol 2013, 166:56-60.

50. Silva AL, Re C, Dietrich C, Fuhrmeister IP, Pimentel A, Corleta HV: Impact of tubal ligation on ovarian reserve as measured by anti-Mullerian hormone levels: a prospective cohort study. Contraception 2013, 88:700-705.

51. Duhan N, Sirohiwal D: Uterine myomas revisited. Eur J Obstet Gynecol Reprod Biol 2010, 152:119-125.

52. Siddle N, Sarrel P, Whitehead M: The effect of hysterectomy on the age at ovarian failure: identification of a subgroup of women with premature loss of ovarian function and literature review. Fertil Steril 1987, 47:94-100.

53. Atabekoglu C, Taskin S, Kahraman K, Gemici A, Taskin EA, Ozmen B, Berker B, Sonmezer M: The effect of total abdominal hysterectomy on serum anti-Mullerian hormone levels: a pilot study. Climacteric 2012, 15:393-397.

54. Lee DY, Park HJ, Kim BG, Bae DS, Yoon BK, Choi D: Change in the ovarian environment after hysterectomy as assessed by ovarian arterial blood flow indices and serum anti-Mullerian hormone levels. Eur J Obstet Gynecol Reprod Biol 2010, 151:82-85.

55. Wang HY, Quan S, Zhang RL, Ye HY, Bi YL, Jiang ZM, Ng EH: Comparison of serum anti-Mullerian hormone levels following hysterectomy and myomectomy for benign gynaecological conditions. Eur J Obstet Gynecol Reprod Biol 2013, 171:368-371.

56. Morelli M, Venturella R, Mocciaro R, Di Cello A, Rania E, Lico D, D'Alessandro P, Zullo F: Prophylactic salpingectomy in premenopausal low-risk women for ovarian cancer: primum non nocere. Gynecol Oncol 2013, 129:448-451. 
57. Findley AD, Siedhoff MT, Hobbs KA, Steege JF, Carey ET, McCall CA, Steiner AZ: Short-term effects of salpingectomy during laparoscopic hysterectomy on ovarian reserve: a pilot randomized controlled trial. Fertil Steril 2013, 100:1704-1708.

58. Hunter LA: Exploring the role of uterine artery embolization in the management of postpartum hemorrhage. J Perinat Neonatal Nurs 2010 24:207-214

59. Lupattelli T, Basile A, Garaci FG, Simonetti G: Percutaneous uterine artery embolization for the treatment of symptomatic fibroids: current status. Eur J Radiol 2005, 54:136-147.

60. Hehenkamp WJ, Volkers NA, Broekmans FJ, de Jong FH, Themmen AP, Birnie E, Reekers JA, Ankum WM: Loss of ovarian reserve after uterine artery embolization: a randomized comparison with hysterectomy. Hum Reprod 2007, 22:1996-2005.

61. Arthur R, Kachura J, Liu G, Chan C, Shapiro H: Laparoscopic myomectomy versus uterine artery embolization: long-term impact on markers of ovarian reserve. J Obstet Gynaecol Can 2014, 36:240-247.

62. Tamarit G, Lonjedo E, Gonzalez M, Tamarit S, Domingo S, Pellicer A: Combined use of uterine artery embolization and local methotrexate injection in interstitial ectopic pregnancies with poor prognosis. Fertil Steril 2010, 93(1348):1348 e1341-1348 e1344.

63. Iwase A, Nakamura T, Nakahara T, Goto M, Kikkawa F: Anti-Mullerian Hormone and Assessment of Ovarian Reserve After Ovarian Toxic Treatment: A Systematic Narrative Review. Reprod Sci 2014. [Epub ahead of print].

64. Lambalk CB, van Disseldorp J, de Koning CH, Broekmans FJ: Testing ovarian reserve to predict age at menopause. Maturitas 2009, 63:280-291.

65. Alborzi S, Momtahan M, Parsanezhad ME, Dehbashi S, Zolghadri J: A prospective, randomized study comparing laparoscopic ovarian cystectomy versus fenestration and coagulation in patients with endometriomas. Fertil Steril 2004, 82:1633-1637.

66. Beretta P, Franchi M, Ghezzi F, Busacca M, Zupi E, Bolis P. Randomized clinical trial of two laparoscopic treatments of endometriomas: cystectomy versus drainage and coagulation. Fertil Steril 1998, 70:1176-1180.

67. Hart R, Hickey M, Maouris P, Buckett W, Garry R: Excisional surgery versus ablative surgery for ovarian endometriomata: a Cochrane Review. Hum Reprod 2005, 20:3000-3007.

doi:10.1186/1477-7827-12-125

Cite this article as: Iwase et al:: Assessment of ovarian reserve using antiMüllerian hormone levels in benign gynecologic conditions and surgical interventions: a systematic narrative review. Reproductive Biology and Endocrinology 2014 12:125.

\section{Submit your next manuscript to BioMed Central and take full advantage of:}

- Convenient online submission

- Thorough peer review

- No space constraints or color figure charges

- Immediate publication on acceptance

- Inclusion in PubMed, CAS, Scopus and Google Scholar

- Research which is freely available for redistribution 